\title{
Ação reguladora da União e qualidade do ensino obrigatório (Brasil, 1988-2007)
}

\section{Regulatory action of the Union and the quality of obligatory teaching (Brazil, 1988-2007)}

\author{
Dirce Nei Teixeira de Freitas*
}

\begin{abstract}
RESUMO
A qualidade do ensino obrigatório no Brasil é abordada mediante consideração de políticas expressas na ação reguladora normativa da União nos últimos vinte anos, especificamente no que diz respeito ao acesso e permanência nesse ensino. Considera-se essa ação reguladora como importante componente do complexo processo social de "morfogênese normativa" cuja conseqüência, conclui-se, precisa ser objeto de avaliação pelos Conselhos de Educação, assim como as concepções e lógicas subjacentes às políticas educacionais no país. Também a sua maior ou menor concorrência para a efetivação do direito à educação, bem como para a qualificação do ensino obrigatório e a democratização de sua gestão.

Palavras-chave: Ensino Fundamental, direito à educação, avaliação educacional.
\end{abstract}

\begin{abstract}
The quality of the obligatory schooling in Brazil has been approached considering the politics expressed in/by the regulatory action of the State in the last twenty years. It is specifically focused on determining the promotion of access and permanence in that level of education. That regulatory action is considered an important component of the complex social process of "normative morphogenesis", and its consequences, in conclusion, need to be an object of evaluation for the Education Council,

* Professora adjunta da Universidade Federal da Grande Dourados.

E-mail: dircenei@terra.com.br.
\end{abstract}


as well as the underlying conceptions and logics in the country's education of politics. It has been also verified that its largest or smallest contribution to the realization of the right to education is useful for the qualification of the obligatory schooling and the democratization of its administration. Key words: basic education, right to education, education evaluation.

Obrigatoriedade e qualidade de ensino são temas bastante tratados na educação brasileira, porém não esgotados. Ambos aparecem historicamente associados ao desafio da garantia e da efetivação do direito à educação. Nos países latino-americanos, o tema qualidade do ensino recebeu maior atenção no início dos anos de 1990 (RISOPATRON, 1991; SCHMELKES, 1994), tendo como principais referências a intensificação da preocupação com essa questão na década de 1980 nos Estados Unidos e em países europeus (DIKER, 1996), e o marco de educação para todos (JOMTIEN, 1990; DAKAR, 2000).

Os debates em torno desses temas têm sido instrumentados por relatórios de organismos internacionais, avaliações nacionais, avaliações e estudos comparativos internacionais, bem como pelas iniciativas de definição de indicadores de qualidade da educação no âmbito internacional (PANORAMA, 2007). Verifica-se ampla concordância a respeito da polissemia do termo qualidade e de seu emprego muitas vezes subjetivo, sendo múltiplos os esforços no sentido de precisá-lo, conforme apontam Dourado, Oliveira e Santos (2007).

As posições da própria Unesco com relação à qualidade da educação evoluíram da idéia de educação integrada e abrangente do Relatório Jacques Delors/1995 para a da educação de boa qualidade como direito humano e apoio a uma abordagem de direitos para todas as atividades educacionais/2003 (EDUCAÇÃO, 2007). Matsuura, diretor geral da Unesco (RELATÓRIO, 2005, p. 5,6$)$ ressalta que a "[...] qualidade deve ser analisada à luz da definição de cada sociedade sobre o objetivo da educação" e "[...] deve ser aprovada no teste de eqüidade". Considerando não resolvida a questão do significado da qualidade, o Relatório (p. 39) afirma que "[...] uma conclusão clara é que boa qualidade na educação [...] deve facilitar a aquisição de conhecimentos, habilidades e atitudes que têm valor intrínseco e que também ajudam no encaminhamento de metas humanas importantes". A qualidade deve reunir respeito aos direitos, relevância, pertinência, eqüidade, eficiência e eficácia (EDUCAÇÃO, 2007).

No Brasil, a obrigatoriedade e a qualidade adquiriram maior relevo no contexto da redemocratização da sociedade brasileira (década de 1980). Explícitos no texto constitucional de 1988 (BRASIL, 2007a), tornaram-se prioritários no Plano Decenal de Educação para Todos/1993 e no Plano Nacional de Educação/2001 (BRASIL, 2007b). No recente Plano de Desenvolvimento da Educação Básica (PDE) e Plano de Metas Compromisso Todos pela Educação a 
qualidade da educação é anunciada como eixo central. Programada para 2008, a Conferência Nacional de Educação tem como proposta a "mobilização nacional pela qualidade e valorização da educação básica". (BRASIL, 2007c)

Na literatura educacional brasileira são diversos os enfoques sobre um e outro tema, citando-se Oliveira e Araújo (2003), Soares (2001; 2005), Klein (2006), Campos, Füllgraf e Wiggers (2006), Stromquist (2007) e Alves (2007). ${ }^{1}$

Importante contribuição a respeito foi trazida por Beisiegel (1993, 1999, 2005), que contrapôs ao discurso hegemônico da "perda da qualidade" do ensino público uma argumentação, historicamente fundamentada, relativa ao insucesso brasileiro na criação da escola para as classes populares. O problema da qualidade de ensino consistiria nos desafios inerentes a uma nova situação escolar no cerne da qual estaria o processo de construção de um povo. $\mathrm{O}$ autor ressalta o que representa em termos de oportunidade a expansão da oferta do ensino fundamental no país.

Reconhecendo a importância, atualidade e complexidade do tema qualidade, propõe-se abordá-lo neste texto pelo ângulo das políticas públicas para o ensino obrigatório expressas na/pela regulação normativa geral (da União), tomando-se como marco inicial a promulgação do texto constitucional vigente no Brasil (1988). Foca-se o "Estado-regulador"2 brasileiro, buscando-se apreendê-lo "em ação" (JOBERT e MÜLLER, 1987). O pressuposto é que a regulação normativa geral é fator importante do complexo processo social de "morfogênese normativa", via inovação e transgressão de normas (SZTOMPKA, 1998). Os atos normativos constituem expressão jurídica das políticas públicas (DUARTE, 2007); ou seja, da ação-inação pública com as suas complexas e contraditórias lógicas processuais, institucionais, "instituintes" e legitimadoras (BARROSO, 2006). Na velha e prolífera via normativa, importante faceta do "Estado-regulador" brasileiro, consideram-se as escolhas estatais e administrativas para qualificar acesso e permanência no ensino obrigatório.

${ }^{1}$ Também publicações estrangeiras no país repercutem no debate, como a de Enquita (1997), que apontou sentidos e significados históricos do discurso sobre a qualidade, e de Marchesi et. al (2003, p. 20), que recomendam como primeira aproximação à definição de qualidade "[...] considerar os objetivos que se coloca a educação", levando-se em conta não só finalidades como o contexto de sua produção e seus processos. Isso pode ser feito segundo distintas ideologias (liberal, igualitarista, pluralista) e enfoques, tendo implicações diversas na definição de indicadores da qualidade na educação. Murillo, Muñoz-Repiso et al. (2007) oferecem uma abordagem teórico-prática da "qualificação da escola", ressaltando o imperativo da invenção da instituição escolar do século XXI.

${ }^{2}$ Ver, a respeito, BARROSO (2005 e 2006). 


\section{O ensino obrigatório no Brasil}

No Brasil, o "ensino obrigatório" limita-se ao "ensino fundamental", segunda etapa da educação básica escolar. Trata-se do ensino que, ao menos formalmente, é antecedido pela educação infantil (creche e pré-escola) e sucedido pelo ensino médio, uma vez que estes atendimentos não têm sido propiciados universalmente. ${ }^{3}$

Tal educação obrigatória consiste num direito-dever tanto das crianças e adolescentes como de suas famílias, da sociedade e do Estado, cabendo a este último eliminar os obstáculos à sua efetivação. Isso porque a Constituição de 1988 estabeleceu, no seu art. 207, o "acesso" ao ensino fundamental como "direito público subjetivo". ${ }^{4}$

Mesmo com estatuto de "direito público subjetivo", a regulação normativa dos anos 1990 e 2000 manteve vinculada a universalização do ensino fundamental à faixa etária de 7 a 14 anos. Para os que não tiveram acesso a esse ensino nessa idade, a obrigatoriedade foi substituída pelo "dever de oferta" do Estado.

Em 2005, o início da obrigatoriedade escolar foi antecipado para seis anos de idade pela Lei n. 11.114/2005, devendo o ensino fundamental ser ampliado para nove anos de duração até o ano de 2010, por força da Lei n. 11.274/2006 (BRASIL, 2007b). Essa medida é importante, pois, como bem mostrou Horta (1998), o estatuto da obrigatoriedade tem sido especialmente importante para a garantia do direito à educação no Brasil. Assim, o ensino obrigatório brasileiro corresponde ao ensino fundamental destinado a crianças de 6 a 12 anos e a adolescentes de 13 a 14 anos, sendo ele também "oferecido" a título de reposição de direito a adolescentes de 15 a 18 anos, a jovens e a adultos. Embora a universalização do acesso se considere praticamente realizada (OLIVEIRA, 2007), para estes últimos não só a oferta está aquém da demanda potencial, como a continuidade de estudos não está assegurada (HADDAD, 2007).

O compromisso com a reposição do direito à educação a essa população e com a sua qualificação continua sem as devidas garantias. A Emenda Constitucional (EC) n. 53, de 19 de dezembro de 2006, estabelece, no $§ 5^{\circ}$ do art. 211, que “A

${ }^{3}$ Dados do IBGE (SÍNTESE, 2007) informam que, em 2006, apenas 15,7\% da população de zero a três anos e $76 \%$ da população de quatro a seis anos freqüentavam creche e pré-escola, sendo de apenas $47,1 \%$ a freqüência líquida ao ensino médio.

${ }^{4}$ O conceito de "direito público subjetivo", a sua construção histórica e implicações políticojurídicas já foram esclarecidos, entre outros, por Horta (1998) e Duarte (2004; 2007), cabendo aqui apenas assinalar que, como conseqüência a esse estatuto, as políticas públicas seguem atribuindo prioridade ao ensino fundamental. 
educação básica pública atenderá prioritariamente ao ensino regular", ou seja, à população que não se encontra em atraso no processo de escolarização. Conforme o $\S 4^{\circ}$ do art. 60 , na redação dada pelo art. $2^{\circ}$ da EC n. 53/2006, a distribuição dos recursos do FUNDEB será efetuada levando-se em conta a totalidade das matrículas no ensino fundamental. Para a educação de jovens e adultos - assim como para a educação infantil e para o ensino médio - isso só fica assegurado a partir do terceiro ano de implantação do Fundo. O Decreto n. 6.094/2007 (BRASIL, 2007c), que dispõe sobre a implementação (em regime de colaboração federativa) do "Plano de Metas Compromisso Todos pela Educação", se limita a fixar a diretriz de "manter programa de alfabetização de jovens e adultos" (inciso XI do art. $2^{\circ}$ ). No entanto, a qualificação da reposição do direito ao ensino obrigatório tornou-se ainda mais urgente com a redução da idade para acesso a "cursos e exames supletivos" (art. 38 da Lei 9.394/1996), uma vez que essa medida retirou significativo contingente de adolescentes com mais de 15 anos do ensino fundamental regular, sem alternativas de qualidade.

Pode-se dizer que importante restrição qualitativa ao ensino declarado "direito público subjetivo" no Brasil advém dessa política de vinculação da universalização do acesso a uma faixa etária, e da reposição daquele direito reduzida a mero "dever de oferta" pelo Estado. Assim, o esforço da sociedade brasileira tem sido insuficiente para compensar a histórica negação do direito à educação no país.

Por outro lado, conforme anuncia a própria denominação "ensino fundamental", o direito público subjetivo à educação no Brasil consiste no "ensino" tido como "fundamental" no contexto da educação básica. Assim, a questão de sua qualidade precisa ser considerada desde a ótica conceitual para desvelar os sentidos e significados desses termos.

$\mathrm{Na}$ Carta Constitucional de 1988, pode-se vislumbrar a concepção de qualidade em vários dispositivos. $\mathrm{O}$ art. $6^{\circ}$ define a educação como um dos direitos sociais, ou seja, como um direito-dever da sociedade (DUARTE, 2007). Sendo assim, entende-se aqui que a sua qualidade está necessária e intimamente associada a parâmetros de justiça social e à igualdade em valor das pessoas. $\mathrm{O}$ art. 205 define a educação como um direito de todos, com o que a sua qualidade supõe que seja uma prática social efetivamente avessa a exceções, seletividades e exclusões, sendo-lhe essencial a dialética entre o direito à igualdade e o direito à diferença, como pondera Cury (2002). Reconhecida nessa Carta como direito fundamental, um direito humano, a educação presume uma qualidade que implica considerar a própria humanização do homem numa perspectiva de emancipação. ${ }^{5}$ 
O art. 207 define a educação como um dos direitos absolutamente prioritários no conjunto das políticas de proteção integral à criança e ao adolescente, com o que a sua qualidade depende de que, de fato, concorra para tal proteção e alcance a todo infante e adolescente, ou seja, à população de 0 a 18 anos nos termos da Lei n. 8.069, de 1990 (BRASIL, 2007b). A restrição acima contradita o disposto nessa Lei.

No art. $1^{\circ}$ da Lei n. 9.394/1996 - LDB/1996 (BRASIL, 2007b), a educação é definida em sentido amplo, compreendendo a "educação escolar" e seus vínculos necessários com o "mundo do trabalho e a prática social". Finalidades e princípios norteadores da educação escolar estão fixados nos arts. 205 e 206 da CF/1988 e nos arts. $2^{\circ}$ e $3^{\circ}$ da LDB/1996, que introduz a concepção brasileira de "educação básica" na norma legal brasileira e fixa seu objetivo (art. 22). O significado do básico nessa educação condiciona o escopo do ensino obrigatório brasileiro.

A concepção de "ensino", por sua vez, pode ser inferida das diretrizes específicas para o ensino fundamental e das normas legais e regulamentares expedidas nas duas últimas décadas, no país. A qualidade buscada no ensino fundamental está sinalizada pelo seu objetivo de propiciar a "formação básica do cidadão", mediante a garantia de aspectos formativos indicados no art. 32 da LDB/1996. Também as diretrizes para o currículo (BRASIL, 2007b, 2007d) operam no dimensionamento normativo da natureza do quinhão da educação escolar cujo acesso se tornou direito público subjetivo no Brasil.

Não é proposta deste artigo considerar o conteúdo histórico materializado nas normas tanto da "educação" como do "ensino", bastando aqui assinalar que esses conceitos são importantes para definir a qualidade do ensino obrigatório.

Cabe lembrar que, no contexto internacional, a "educação obrigatória" corresponde hoje à "educação básica", cuja duração varia em diferentes países. Conforme se vê em Educação (2007, p. 34), a educação básica não é "[...] uma característica exclusiva da educação obrigatória", pois se trata de uma visão mais ampla. Está aí um importante desafio para a educação brasileira.

\section{Acesso e permanência}

O Brasil tem conquistado avanços importantes no ensino obrigatório, mas a sua qualidade segue problematizada no tocante à proficiência, permanência, progressão, conclusão, duração e até mesmo ao acesso. A quase universalização deste representou um importante ganho. Dados do IBGE (SÍNTESE, 2007) informam que, em 
2006, a taxa líquida de freqüência ao ensino fundamental era de $94,8 \%$. Embora a não-freqüência na faixa de 7 a 14 anos seja baixa (de 5,2\%), não é irrelevante quando considerada sob a perspectiva da violação de direitos. A "universalização com qualidade" do ensino fundamental até o ano de 2006, conforme diretriz do Plano Nacional de Educação (BRASIL, 2001), não foi alcançada. Todavia, fora do "mundo desenvolvido", nenhum país atingiu as metas mensuráveis de educação para todos (RELATÓRIO, 2005).

No Brasil, a defasagem na correlação idade/série freqüentada ainda era, em 2006, de 25,7\%. Atingia 8,3 de milhões de estudantes num universo de 32,5 milhões, sendo mais acentuada nas últimas séries do ensino fundamental. Mesmo alta, essa taxa foi comemorada pela União, pois representa expressiva redução da registrada em 1996, que era da ordem de 43,9\%. Concorreram para essa redução estratégias das políticas de correção de fluxo da União e de unidades da federação, no período posterior a 1996.

Por outro lado, não foi possível comemorar ganhos significativos nos níveis de proficiência dos alunos nos componentes curriculares avaliados por meio do SAEB e Prova Brasil (BRASIL, 2007e). Embora este seja apenas um aspecto da trama da qualidade de ensino, a proliferação de sistemas nacionais e iniciativas internacionais de avaliação mostra que a ele se tem dado grande atenção, sendo enfatizado sempre que se trata de "êxito" ou "fracasso escolar" (KOVACS, 2004).

A conclusão do ensino obrigatório tem sido outro problema. O IBGE mostra que em 2006 a população de 15 anos de idade tinha, em média, 6,5 anos de estudo quando, por força da obrigatoriedade, deveria ter concluído 8 anos de escolarização. Também a duração da obrigatoriedade escolar, de apenas 9 anos, é baixa e apresenta clara desvantagem em relação a 26 países da região latino-americana e caribenha, nos quais ela fica entre 10 e 13 anos (EDUCAÇÃO, 2007).

Mas, a necessária ampliação do ensino obrigatório precisa ser promovida de modo tal que a qualidade no acesso não se limite ao ingresso na escola. Deve abarcar também o acesso a recursos materiais, políticos e culturais desse locus e de seu contexto; em outras palavras, acesso às estruturas e mediações do processo de escolarização e, sobretudo, a bens culturais e à formação básica comprometida com a emancipação pessoal e social.

A política de promoção do "acesso" ao ensino obrigatório expressa na regulação normativa posterior a 1988 é sintetizada no quadro 1 .

A qualificação do acesso ao ensino obrigatório foi objeto da regulação normativa da União ao longo do período. Essa produção normativa centralizada, bem como a descentralizada e os reajustamentos que geram ou não no sistema educacional exigem avaliações, para a devida apreensão da materialidade do Estado-regulador brasileiro na área. Entende-se que devam os Conselhos de Educação empenhar-se nela, em razão de suas funções e seus compromissos com a democratização da educação e sua gestão. 
QUADRO 1 - ESTRATÉGIAS, MECANISMOS E INSTRUMENTOS DA POLÍTICA DE PROMOÇÃO DO “ACESSO” AO ENSINO OBRIGATÓRIO - BRASIL (1988-2007)

\begin{tabular}{|c|c|c|}
\hline ESTRATÉGIAS & MECANISMOS & INSTRUMENTOS \\
\hline $\begin{array}{l}\text { Rearranjos } \\
\text { do regime de } \\
\text { colaboração } \\
\text { federativa e do } \\
\text { financiamento } \\
\text { educacional }\end{array}$ & $\begin{array}{l}\text { - estabelecimento de competências dos } \\
\text { entes federativos } \\
\text { - divisão de incumbências entre instâncias } \\
\text { administrativas } \\
\text { • determinação de objetos da colaboração } \\
\text { federativa } \\
\text { - mudança na estrutura do financiamento } \\
\text { - instituição do FUNDEF (1998-2006) e } \\
\text { FUNDEB (2007) } \\
\text { - gratuidade do ensino fundamental } \\
\text { orientada para a diminuição de custos e } \\
\text { igualdade de condições para o acesso }\end{array}$ & $\begin{array}{l}\text { • Emendas Constitucionais } \\
\text { de n. 14/1996, n. 19/1998 e } \\
\text { n. 53/2006 } \\
\text { • Leis ordinárias n. 9.131/96, } \\
\text { n. 9.394/96 (LDB), } \\
\text { n. 9.424/1996 (FUNDEF), } \\
\text { n. 10.172/2001 (PNE), } \\
\text { n. 11.494/2007 (FUNDEB) } \\
\text { • Decreto n. 6.094/2007 } \\
\text { - Lei n. 10.832/2003 } \\
\text { (Salário-Educação) } \\
\text { - Lei n. 11.494/2007 } \\
\text { (FUNDEB) }\end{array}$ \\
\hline $\begin{array}{l}\text { Responsabili- } \\
\text { zação pública } \\
\text { e privada e mobi- } \\
\text { lização social }\end{array}$ & $\begin{array}{l}\text { - determinação de responsabilidades } \\
\text { públicas e privadas } \\
\text { • fortalecimento da obrigatoriedade } \\
\text { • indicação de meios pré-efetivação do } \\
\text { direito público subjetivo (chamada, zelo } \\
\text { pela freqüência, proximidade da escola) } \\
\text { • estabelecimento de um "sistema de } \\
\text { garantias" (DIGIÁCOMO, 2004) } \\
\text { • instrumentação jurídica, política, admi- } \\
\text { nistrativa e técnico-burocrática } \\
\text { • mobilização social pela melhoria da } \\
\text { qualidade da educação básica }\end{array}$ & $\begin{array}{l}\text { - Lei n. 8.069/1990 (ECA) } \\
\text { - Lei n. 9.394/1996(LDB) } \\
\text { - Lei n. 10.287/2001 (PNE) } \\
\text { - Decreto n. 6.094/2007 }\end{array}$ \\
\hline
\end{tabular}




\begin{tabular}{|c|c|c|}
\hline \multicolumn{3}{|c|}{$\begin{aligned} \text { QUADRO } 1 \text { - } & \text { ESTRATÉGIAS, MECANISMOS E INSTRUMENTOS DA POLÍTICA DE PROMOÇÃO } \\
& \text { DO “ACESSO" AO ENSINO OBRIGATÓRIO - BRASIL (1988-2007) }\end{aligned}$} \\
\hline ESTRATÉGIAS & MECANISMOS & INSTRUMENTOS \\
\hline $\begin{array}{l}\text { Reordenação da } \\
\text { Gestão }\end{array}$ & $\begin{array}{l}\text { - determinação de prioridade ao ensino } \\
\text { fundamental } \\
\text { • exigência de regularidade na sua oferta } \\
\text { • descentralização e desconcentração } \\
\text { • municipalização } \\
\text { - autonomia escolar } \\
\text { - gestão participativa e democrática }\end{array}$ & $\begin{array}{l}\text { - Emenda Constitucional } \\
\text { n. } 19 / 1998 \\
\text { - Lei n. 10.172/2001 (PNE) } \\
\text { - Decreto n. 6.094/2007 }\end{array}$ \\
\hline $\begin{array}{l}\text { Reordenação } \\
\text { Curricular }\end{array}$ & $\begin{array}{l}\text { - determinações curriculares, começando } \\
\text { pela exigência de fixação de “conteúdos } \\
\text { mínimos” (art. } 210 \text { da CF/1988), que } \\
\text { autorizam a regulação normativa e ava- } \\
\text { liativa do currículo principiada no texto } \\
\text { constitucional, continuada nos textos } \\
\text { legais e nos regulamentares do CNE e } \\
\text { direcionada teórico-metodologicamente } \\
\text { pelos parâmetros curriculares do MEC } \\
\text { e matriz de referência de avaliação } \\
\text { (SAEB) do INEP }\end{array}$ & $\begin{array}{l}\text { • Constituição } 1988 \\
\text { • Leis ordinárias } \\
\text { n. 9.394/1996 (LDB), } \\
\text { n. 9.475/1997, } \\
\text { n. 10.328/2001, } \\
\text { n. 10.793/2003, } \\
\text { n. 10.639/2003, } \\
\text { • Parecer CEB/CNE } \\
\text { n. 04/1998 } \\
\text { - Resolução CEB/CNE } \\
\text { n. 02/1998 } \\
\text { • Parecer CEB/CNE } \\
\text { n. 11/2000 } \\
\text { - Resolução CEB/CNE } \\
\text { n. 01/2000 } \\
\text { - Parecer CEB/CNE } \\
\text { n. 06/2005 }\end{array}$ \\
\hline $\begin{array}{l}\text { Ampliação da } \\
\text { Obrigatoriedade }\end{array}$ & $\begin{array}{l}\text { - determinação do início da obrigatorieda- } \\
\text { de escolar aos seis anos de idade } \\
\text { - ampliação da duração do ensino funda- } \\
\text { mental }\end{array}$ & $\begin{array}{l}\text { - Lei n. } 11.114 / 2005 \\
\text { - Lei n. } 11.274 / 2006\end{array}$ \\
\hline
\end{tabular}

A política de promoção do acesso recentemente ampliou o alcance demográfico do direito público subjetivo à educação, o que representa importante ganho qualitativo na educação brasileira. Mas a face adversa dessa estratégia estatal está no fato de que a ampliação da titularidade do direito se dá na esfera do "ensino" em prejuízo da "educação". De um ensino cujas mazelas são 
amplamente conhecidas e reiteradas pelas estatísticas, avaliações (BRASIL, 2007e), análises e estudos educacionais como os de Ribeiro (1991), Ferraro (1999, 2004), Arroyo (2000), Sposati (2000), Franco, Bonamino e Fernandes (2002), Soares (2004, 2005), Oliveira e Araújo (2005).

Marcado pela exclusão, seletividade, iniqüidade, ineficácia, ineficiência e baixa efetividade, o ensino obrigatório está longe de ter a qualidade que a concepção de acesso acima mencionada aponta. Sem o devido enfrentamento de tais problemas, a estratégia de ampliação da obrigatoriedade reproduz características históricas da expansão desse ensino no país, especialmente a heterogeneidade, improvisação, insuficiência, seletividade, discriminação, qualidade insatisfatória e formalização.

Desse modo, a ampliação do ensino obrigatório pode não constituir uma alternativa de escolarização qualitativamente superior àquela que tem sido propiciada à criança de seis anos pela educação infantil. Por outro lado, essa ampliação não se dá no sentido da reposição do direito violado de adolescentes com mais de 14 anos.

O quadro 2 sintetiza a política de promoção da permanência dos estudantes na escola manifesta na regulação normativa posterior a 1988. A permanência compreende a freqüência às aulas durante o ano letivo, de modo que o estudante não incorra na situação de "abandono escolar", e também a perseverança na trajetória que vai do início ao término da etapa de ensino, não se verificando a situação de "evasão escolar".

QUADRO 2 - ESTRATÉGIAS, MECANISMOS E INSTRUMENTOS DA POLÍTICA DE PROMOÇÃO DA "PERMANÊNCIA" NO ENSINO OBRIGATÓRIO - BRASIL (1988-2007)

\begin{tabular}{lll}
\hline ESTRATÉGIAS & \multicolumn{1}{c}{ MECANISMOS } & \multicolumn{1}{c}{ INSTRUMENTOS } \\
\hline & • responsabilização pela irregularidade na & Constituição Federal \\
& oferta & Leis n. 8.069/90 \\
Regularidade na & absoluta prioridade da efetivação do direito & (ECA) e \\
oferta do ensino & à educação das crianças e adolescentes & n. 9.394/96 (LDB), \\
& cumprimento dos dias letivos e horas de & Lei n. 10.172/2001 \\
& ensino & (PNE) \\
\hline
\end{tabular}

Leis n. 8.069/90

- fixação da freqüência exigida (ECA),

Freqüência à escola
- controle compartilhado entre pais, escola, Conselho Tutelar e Juizado competente

- acompanhamento individual com registros da freqüência e razões da não-freqüência n. 9.394/96 (LDB),

n. $10.287 / 2001$,

Lei n. 10.172/2001

(PNE) 
$\begin{array}{ll}\text { QUADRO } 2- & \text { ESTRATÉGIAS, MECANISMOS E INSTRUMENTOS DA POLÍTICA DE PROMOÇÃO } \\ & \text { DA “PERMANÊNCIA" NO ENSINO OBRIGATÓRIO - BRASIL (1988-2007) }\end{array}$

\begin{tabular}{|c|c|c|}
\hline ESTRATÉGIAS & MECANISMOS & INSTRUMENTOS \\
\hline $\begin{array}{l}\text { Flexibilização da } \\
\text { organização do } \\
\text { ensino e da pro- } \\
\text { gressão escolar }\end{array}$ & $\begin{array}{l}\text { - formas de organização baseadas em critérios } \\
\text { pedagógicos } \\
\text { - regimes de progressão continuada e parcial } \\
\text { • procedimentos de classificação e reclassi- } \\
\text { ficação } \\
\text { • aproveitamento de estudos concluídos com } \\
\text { êxito } \\
\text { - aceleração de estudos }\end{array}$ & $\begin{array}{l}\text { Lei n. 9.394/96 (LDB) } \\
\text { Lei n. 10.172/2001 } \\
\text { (PNE) }\end{array}$ \\
\hline $\begin{array}{l}\text { Promoção da } \\
\text { aprendizagem }\end{array}$ & $\begin{array}{l}\text { - incumbências docentes e escolares relativas } \\
\text { à aprendizagem } \\
\text { • incumbências docentes e escolares relativas } \\
\text { à provisão e realização da recuperação, } \\
\text { aulas de "reforço" e outras para combate à } \\
\text { repetência } \\
\text { - incumbências docentes e escolares de } \\
\text { informar os pais sobre a execução do projeto } \\
\text { pedagógico da escola e sobre o aproveita- } \\
\text { mento escolar de seus filhos } \\
\text { - criação de condições próprias de aprendiza- } \\
\text { gem a estudantes com mais de } 14 \text { anos } \\
\text { - implantação de sistema de monitoramento } \\
\text { • estabelecimento de resultados concretos a } \\
\text { atingir } \\
\text { - fixação de prazo para a alfabetização (até } 8 \\
\text { anos) } \\
\text { - acompanhamento individual do desempenho } \\
\text { por meio de avaliações periódicas }\end{array}$ & $\begin{array}{l}\text { Lei n. } 9.394 / 96 \text { (LDB) } \\
\text { Lei n. } 10.172 / 2001 \\
\text { Decreto n. 6.094/2007 } \\
\text { Portaria Normativa } \\
\text { 10/2007 }\end{array}$ \\
\hline $\begin{array}{l}\text { Ampliação do } \\
\text { tempo na escola }\end{array}$ & $\begin{array}{l}\text { - tempo integral } \\
\text { - permanência do estudante na escola além da } \\
\text { jornada regular }\end{array}$ & $\begin{array}{l}\text { Leis n. 9.394/96 } \\
\text { (LDB) e Lei } \\
\text { n. 10.172/2001 (PNE) } \\
\text { Decreto n. 6.094/2007 }\end{array}$ \\
\hline
\end{tabular}




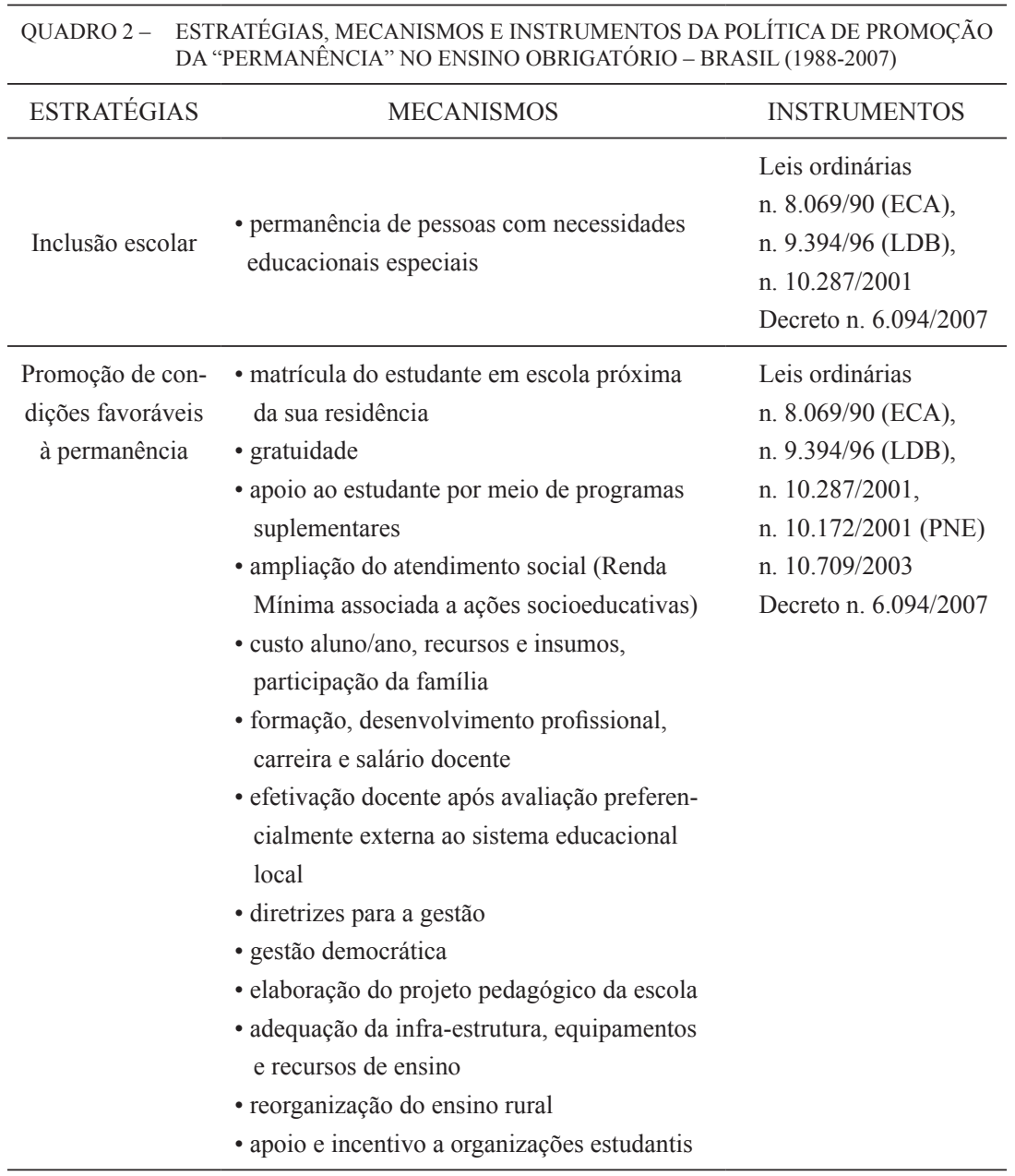

Verifica-se que a regulação normativa da União tem contemplado o desafio da promoção da permanência do estudante no ensino obrigatório, traçando diretrizes importantes para a superação do "fracasso escolar" (não-conclusão, conclusão tardia, conclusão sem domínio de conhecimentos e competências básicas). Também a conseqüência dessas diretrizes precisa ser avaliada pelos Conselhos de Educação. 


\section{Finalizando}

A qualificação do acesso e da permanência no ensino obrigatório é indispensável para produzir-se o êxito escolar. Contudo, não bastam "reformas" e "apoios" estritamente escolares. São necessárias políticas econômicas e sociais contra determinadas formas de "exclusão" (LAHIRE, 2004). No Brasil, é indispensável o devido enfrentamento da pobreza, como mostram Andrade e Daches (2007), sendo as políticas focalizadas e emergenciais (Bolsa-escola, Bolsa-família) necessárias, mas insuficientes.

Diversos estudos e análises evidenciam a insuficiência do financiamento educacional. Estudo da Organização para a Cooperação e o Desenvolvimento Econômico (OCDE) de 2007 mostrou que, entre 36 países, o Brasil encontrase em último lugar no gasto estudante/ano. Com um valor de $\mathrm{R} \$ 2.749$ sua aplicação representa um décimo do valor praticado pelos Estados Unidos. O Chile, outro país da América do Sul a entrar nesse estudo, tem um gasto de R\$ 6.043 estudante/ano. No ensino fundamental, o Brasil fica à frente apenas da Turquia. Fica em último lugar no gasto com o ensino médio. $\mathrm{O}$ gasto brasileiro em educação é de 3,9\% do PIB, sendo que os Estados Unidos gastam 7,4\% e Israel, o primeiro colocado, gasta $8 \%$ (FOLHA, 2007).

Castro (2007) mostra que o gasto público com educação no Brasil passou de 4,01\% do PIB em 1995 para apenas 4,05\% em 2005. A prioridade dada ao ensino fundamental fez com que, dos $2,16 \%$ do PIB em 1995, se chegasse a $2,35 \%$ em 2005, uma elevação de somente 0,19 pontos percentuais em 11 anos. Conclui que (Ibid., p. 870) "[...] a prioridade macroeconômica da área da educação pouco se alterou, apesar do discurso em prol da educação".

Duarte (2005) afirma ter sido baixa a capacidade da "engenharia política do financiamento da educação após 1996" na redução das desigualdades de recursos intersistemas de ensino e interescolares, tendo a União seu papel de metarregulação aumentado, porém sem ampliar o investimento direto na educação básica.

Saviani (2007) alerta que o FUNDEB representa ganho em gestão e não financeiro para a educação básica, pois aumenta em apenas 36,3\% o montante de recursos financeiros enquanto cresce em $56,6 \%$ o quantitativo de estudantes atendidos. Assim, não terá força para alterar o status quo vigente. Apesar disso, o PDE tem como preocupação central o problema da qualidade da educação básica brasileira. Para tanto, o autor sugere a aplicação de $8 \%$ do PIB na educação desde já, considerando os positivos reflexos disso na escola, no seu trabalho pedagógico e na aprendizagem dos alunos. 
Decorridos 17 anos do compromisso de educação para todos (firmado em JOMTIEN, 1990) e sete anos da revisão daquelas metas (DAKAR, 2000), o Brasil protela para 2022 (mais 15 anos) o alcance da meta de educação básica para todos. O "Compromisso Todos pela Educação" pretende atingir até 2022 as seguintes metas: toda criança e jovem de 4 a 17 anos na escola; toda criança plenamente alfabetizada até os 8 anos; todo aluno com aprendizado adequado à sua série; todo aluno com o ensino médio concluído até os 19 anos.

Cabe aqui lembrar que o relatório sobre o direito à educação do Conselho Econômico e Social das Nações Unidas enfatiza que os governos têm obrigação de "financiar adequadamente" a educação das crianças no período de seu crescimento, pois a reparação retrospectiva da privação desse direito não pode ser realizada de fato (TOMASEVSKI, 2004).

Finalmente, as políticas expressas na regulação normativa da União valorizam o caminho da indução das administrações subnacionais e locais, constrangendo-as à adesão a regras do jogo centralmente definidas e centralmente instrumentadas pelo planejamento estratégico, pela "medida-avaliaçãoinformação" e pela "assistência técnica". A concentração do poder decisório, regulador e disciplinador no âmbito da União apóia-se no discurso legitimador sobre gestão participativa e mobilização social. A regulação normativa pela União, ampliada, fragiliza a autonomia dos entes federativos e reforça a intervenção reguladora centralizada. Em lugar de promover competências técnico-burocráticas nos espaços subnacionais, a tendência é concentrá-las nas estruturas da União, tendo as novas tecnologias da comunicação como recursos essenciais de regulação.

A conseqüência dessa regulação precisa ser avaliada no que propicia tanto em termos de "invenção" como de "transgressão" normativa na educação, assim como as concepções e lógicas subjacentes às políticas educacionais no país. Também a sua maior ou menor concorrência para a efetivação do direito à educação, bem como para a qualificação do ensino obrigatório e a democratização de sua gestão. 


\section{REFERÊNCIAS}

ADORNO, T. W. Educação e emancipação. 2. ed. São Paulo: Paz e Terra, 2000.

ALVES, F. Qualidade na educação fundamental pública nas capitais brasileiras: tendências, contextos e desafios. 2007. Tese (Doutorado em Educação) - Departamento de Educação, Pontifícia Universidade Católica do Rio de Janeiro, Rio de Janeiro.

ANDRADE, C. Y. de; DACHES, J. N. W. Acesso à educação por faixa etária, segundo renda e raça/cor. Cadernos de Pesquisa, São Paulo, v. 37, n. 131, p. 399-422, maio/ ago. 2007.

ARROYO, M. G. Fracasso/sucesso: um pesadelo que perturba nossos sonhos. Em Aberto, Brasília, v. 17, n.71, p. 33-40, jan. 2000.

BARROSO, J. O Estado, a educação e a regulação das políticas públicas. Educação \& Sociedade, Campinas, CEDES, v. 26, n. 92 - especial, p. 715-718, out. 2005.

. (Org.). A regulação das políticas públicas de educação: espaços, dinâmicas e actores. Portugal: Educa, 2006.

BEISIEGEL, C. de R. Considerações a propósito de um projeto educacional. São Paulo em Perspectiva, São Paulo, v. 7, n. 1, p. 38-49, jan./mar. 1993.

. Avaliação e qualidade do ensino. In: BICUDO, Maria Aparecida V.; SILVA JÚNIOR, C. A. da (Org.). Formação do educador: organização da escola e do trabalho pedagógico. São Paulo: UNESP, 1999. p. 35-41.

. A qualidade do ensino na escola pública. Brasília: Líber Livro, 2005.

BRASIL. Senado Federal. Legislação. Disponível em: <http://www.senado.gov.br/sf/ legislacao/const>. Acesso em: 26/9/2007a.

. Senado Federal. Pesquisa Portal (Legislação) - SICON. Disponível em: $<$ http:// www6.senado.gov.br/sicon>. Acesso em: 26/9/2007b.

. Ministério da Educação. Disponível em: <http://www. mec.gov.br >. Acesso em: 26/9/2007c.

. Conselho Nacional de Educação - CNE. Disponível em: <http://portal.mec.

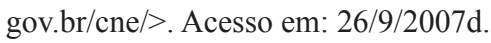

. Instituto Nacional de Estudos e Pesquisas Educacionais Anísio Teixeira - INEP. Disponível em: <http://www. inep.gov.br>. Acesso em: 26/9/2007e. 
CAMPOS, M.; FÜLLGRAF, J.; WIGGERS, V. A qualidade da educação infantil brasileira: alguns resultados de pesquisa. Cadernos de Pesquisa, São Paulo, v. 36, n. 127, p. 87-128, abr. 2006.

CASTRO, J. A. de. Financiamento e gasto público na educação básica no Brasil: 1995-2005. Educação \& Sociedade, Campinas, v. 28, n. 100 - especial, p. 857-876, out. 2007.

CURY, C. R. J. A educação como desafio na ordem jurídica. In: LOPES, E. M. T; FARIA FILHO, L. M.; VEIGA, C. G. 500 anos de educação no Brasil. 2. ed. Belo Horizonte: Autêntica, 2000. p. 567-584.

. Direito à educação: direito à igualdade, direito à diferença. Cadernos de Pesquisa, São Paulo, n. 116, p. 245-252, jul. 2002.

DIGIÁCOMO, M. J. Instrumentos jurídicos para garantia do direito à educação. In: LIBERATI, W. D. (Org.). Direito à educação: questão de justiça. São Paulo: Malheiros, 2004. cap. 6, p. 273-375.

DIKER, Gabriela. La evaluación de la calidad como dispositivo de regulación social. Buenos Aires, 1998. (mimeo.).

DOURADO, L. F.; OliveirA, J. F. de; SAnTOS, C. de A. A Qualidade da educação: definições. Brasília, 2007. Disponível em: <www.inep.gov.br>. Acesso em: 13/9/2007.

DUARTE, C. S. Direito público subjetivo e políticas educacionais. São Paulo em Perspectiva, São Paulo, v. 18, n. 2, p. 113-118, 2004. Disponível em: <www.scielo. br/>. Acesso em: 20/3/2006.

. A educação como um direito fundamental de natureza social. Educação \& Sociedade, Campinas, v. 28, n. 100 - especial, p. 691-713, out. 2007.

DUARTE, M. R. T. Regulação sistêmica e política de financiamento da educação básica. Educação \& Sociedade, Campinas, v. 26, n. 92, p. 821-839, out. 2005.

EDUCAÇÃO de qualidade para todos: um assunto de direitos humanos. Brasília: UNESCO/OREALC, 2007.

ENGUITA, M. F. O discurso da qualidade e a qualidade do discurso. In: GENTILI, P. A. A.; SILVA, T. T. da (Org.). Neoliberalismo, qualidade total e educação: visões críticas. 3. ed. Petrópolis: Vozes, 1995. p. 93-110.

FERRARO, A. R. Diagnóstico da escolarização no Brasil. Revista Brasileira de Educação, Campinas, n. 12, p. 22-47, set./out./nov./dez. 1999. 
. Escolarização no Brasil na ótica da exclusão. In: MARCHESI, A. et al. Fracasso escolar: uma perspectiva multicultural. Porto Alegre: ARTEMED, 2004. p. 48-65.

FERRARO, A. R.; MACHADO, N. C. F. Da universalização do acesso à escola no Brasil. Educação \& Sociedade, Campinas, v. 23, n. 79, p. 213-214, ago. 2002.

FOLHA ONLINE. Brasil investe mal e pouco na educação, conclui estudo. Agência Brasil, 18/9/2007. Disponível em: <http://wwwl.folha.uol.com.br>. Acesso em: $18 / 9 / 2007$.

FRANCO, C.; BONAMINO, A.; FERNANDES, C. O SAEB 2001: primeiras investigações. Rio de Janeiro: PUC, 2002. (Documento de trabalho - versão preliminar). Disponível em: <http://www.inep.gov.br>. Acesso em: 24/5/2007.

HADDAD, S. A ação dos governos locais na educação de jovens e adultos. Revista Brasileira de Educação, Rio de Janeiro, v. 12, n. 35, p. 197-211, maio/ago. 2007.

HORTA, J. S. B. Direito à educação e obrigatoriedade escolar. Cadernos de Pesquisa, São Paulo, Fundação Carlos Chagas, n. 104, p. 5-34, jul. 1998.

LAHIRE, B. As origens da desigualdade escolar. In: MARCHESI, A. et al. Fracasso escolar: uma perspectiva multicultural. Porto Alegre: ARTEMED, 2004. p. 69-75.

KLEIN, R. Como está a educação no Brasil? O que fazer? Ensaio: Avaliação e Políticas Públicas em Educação, Rio de Janeiro, v. 14, n. 51, p. 139-171, jun. 2006.

KOVACS, K. O informe da OCDE sobre o fracasso escolar. In: MARCHESI, A. et al. Fracasso escolar: uma perspectiva multicultural. Porto Alegre: ARTEMED, 2004. p. 43-47.

JOBERT, B.; MULLER, P. L'Ëtat en Action. Paris: PUF, 1987.

MURILLO, F. J.; MUÑOZ-REPISO, M. et al. A qualificação da escola: um novo enfoque. Porto Alegre:ARTEMED, 2007.

OLIVEIRA, R. P. de. Educação e cidadania: o direito à educação na Constituição de 1988 da República Federativa do Brasil. Tese (Doutorado em Educação), Universidade de São Paulo, São Paulo, 1995.

. Da universalização do ensino fundamental ao desafio da qualidade: uma análise histórica. Educação \& Sociedade, Campinas, v. 28, n. 100 - especial, p. 661690, out. 2007. 
OLIVEIRA, R. P. de; ARAUJO, G. C. de. Qualidade do ensino: uma nova dimensão da luta pelo direito à educação. Revista Brasileira de Educação, Rio de Janeiro, n. 28 , p. 5-23, abr. 2005.

PANORAMA sobre a educação 2007: da OCDE. Sumário em português. Disponível em: $<\mathrm{http}: / /$ www.oecd.org/dataoecd/25/7/39316322.pdf $>$. Acesso em: 2/10/2007.

RELATÓRIO de Monitoramento Global de EPT 2005. Educação para todos: o imperativo da qualidade/UNESCO. São Paulo: Moderna, 2005.

RIBEIRO, S. C. A pedagogia da repetência. Estudos Avançados, São Paulo, IEA-USP, v. 5 , n. 12 , p. $7-22$, maio/ago. 1991.

RISOPATRON, V. E. El concepto de calidad de la educacion. Santiago/Chile: UNESCO/OREALC, 1991.

SAVIANI, D. Educação \& Sociedade, Campinas, v. 28, n. 100 - especial, p. 12311255, out. 2007.

SCHMELKES, S. Buscando uma melhor qualidade para nossas escolas. Brasília: MEC, 1994. (Cadernos Educação Básica, Atualidades Pedagógicas, 10).

SEVERINO, A. J. A busca do sentido da formação humana: tarefa da Filosofia da Educação. Educação e Pesquisa, São Paulo, FEUSP, v. 32, n. 3, p. 619-634, set./dez. 2006.

SÍNTESE dos Indicadores Sociais 2007 - Uma análise das condições de vida da população brasileira, 2007. Estudos e Pesquisas: informação demográfica e socioeconômica, Rio de Janeiro, IBGE, n. 21, 2007.

SOARES, J. F. Qualidade e eqüidade na educação básica brasileira: a evidência do SAEB-2001. Archivos Analíticos de Políticas Educativas, v. 12, n. 38, ago. 2004. Disponível em: $<$ http://epaa.asu.edu/epaa/v12n38/.>. Acesso em: 8/12/2005.

. Qualidade e eqüidade na educação básica brasileira: fatos e possibilidades. In: SCHWARTZMAN, Simon; BROCK, Colin (Org.). Os desafios da educação no Brasil. Rio de Janeiro: Nova Fronteira, 2005. p. 91-117.

SPOSATI, A. Exclusão social e fracasso escolar. Em Aberto, Brasília, v. 17, n. 71, p. 21-32, jan. 2000.

STROMQUIST, N. P. de ensino e gênero nas políticas educacionais contemporâneas na América Latina. Educação e Pesquisa, São Paulo, v. 33, n. 1, p. 13-25, jan./abr. 2007. 
SZTOMPKA, P. A sociologia da mudança social. Rio de Janeiro: Civilização Brasileira, 1998.

SCHWARTZMAN, S. Os desafios da educação no Brasil. In: ; BROCK, Colin (Org.). Os desafios da educação no Brasil. Rio de Janeiro: Nova Fronteira, 2005. p. 9-51.

TOMASEVSKI, K. Los derechos economicos, sociales y culturales: el derecho a la educación. Informe de 25 de janeiro de 2004 à Comision de Derechos Humanos do Conselho Econômico e Social das Nações Unidas. Disponível em: $<$ http://www.unhchr. ch>. Acesso em: 16/11/2006.

Texto recebido em 22 set. 2007

Texto aprovado em 15 dez. 2007 